\title{
Effects of regular exercise on asthma control in young adults
}

Heikkinen SAM ${ }^{1}$, Mäkikyrö EMS ${ }^{1}$, Hugg TT ${ }^{1}$, Jaakkola MS ${ }^{2}$, Jaakkola JJK ${ }^{1}$.

1 Center for Environmental and Respiratory Health Research (CERH), University of Oulu, Oulu, Finland

2 Medical Research Center Oulu, Oulu University Hospital and University of Oulu, Oulu, Finland

This is an Accepted Manuscript of an article published by Taylor \& Francis in Journal of Asthma on 05 Oct 2017, available online: https://doi.org/10.1080/02770903.2017.1366510. 


\begin{abstract}
Background: According to our systematic literature review, no previous study has assessed potential effects of regular exercise on asthma control among young adults. We hypothesized that regular exercise improves asthma control among young adults.

Methods: We studied 162 subjects with current asthma recruited from a population-based cohort study of 1623 young adults 20-27 years of age. Asthma control was assessed by the occurrence of asthma-related symptoms, including wheezing, shortness of breath, cough, and phlegm production, during the past 12 months. Asthma symptom score was calculated based on reported frequencies of these symptoms (range 0-12). Exercise was assessed as hours/week.

Results: In Poisson regression, adjusting for gender, age, smoking, environmental tobacco smoke exposure, and education, the asthma symptom score reduced by 0.09 points per 1 hour of exercise/week (95\% CI: 0.00 to 0.17). Applying the "Low exercise" quartile as the reference, "Medium exercise" reduced the asthma symptom score by 0.66 (-0.39 to 1.72), and "High exercise" reduced it significantly by 1.13 (0.03 to 2.22 ). The effect was strongest among overweight subjects. Conclusions: Our results provide new evidence that regular exercising among young adults improves their asthma control. Thus, advising about exercise should be included as an important part of asthma self-management in clinical practise.
\end{abstract}

KEYWORDS: asthma, asthma control, regular exercise, young adults

\title{
Text: 2990 words
}




\section{Introduction}

Asthma is among the most common chronic diseases among young adults in high and medium income countries [1]. Poorly controlled asthma imposes a substantial burden for health care in many parts of the world [2]. Asthma-related health problems make a considerable contribution to disabilities and increase health-care costs [3]. In a large population survey from Australia, poorly controlled asthma was associated with a lower quality of life [4]. Improving asthma control will produce many beneficial health-related effects, including reducing disability, absence from work, and health-care costs, as well as improving the quality of life.

Regular exercise has been shown to have many positive effects on other chronic diseases than asthma, for example by reducing the risk of cardiovascular diseases, diabetes, obesity, hypertension and depression [5]. However, its potential effects on asthma control are still poorly understood [6], and advice to avoid exercising has previously been routinely given to asthmatics because of fear for exercise-induced asthma symptoms. The results of a cross-sectional survey of over 12,500 asthmatic adults from the United States showed that less than one fourth of the participants engaged in physical activity for at least 150 min per week [7]. In addition, a Korean study showed that more than half of the 514 asthmatics did not exercise regularly at all [8]. One reason for low physical activity among adult asthmatics may be the lack of research on how regular exercise will affect asthma control. Based on our systematic review and meta-analysis of clinical trials [6], regular exercise improves maximal oxygen consumption, but evidence on its potential effects on asthma control and/or quality of life was inconclusive although some individual studies showed evidence of improving asthma control. The results on effects on lung function were inconclusive. Small sample sizes, lack of control group, and heterogeneous outcome measures limited the possibility to make any definite conclusions concerning the effects of regular exercise on asthma control. We found that no previous study had assessed potential effects of regular exercise on asthma control among young adults. To fill in this gap of knowledge, we hypothesized that regular exercise is directly related to a better asthma control in young adults.

\section{Methods}

\section{Study design and study population}

This was a population-based cross-sectional study assessing potential effects of regular exercise on asthma control. The baseline study population was from the Espoo Cohort Study that was 
established in 1991 [9]. At the baseline, the cohort members were living in the city of Espoo that is located in the Helsinki metropolitan area, Finland. Espoo is the second largest municipality in South Finland, with a population of 274,500 in 2015 . The baseline source population included all children living in the city of Espoo, Finland, who were born between January 1st, 1984, and December 31st, 1989. In 2010-2011 we conducted the 20-year follow-up with a questionnaire sent to all members of the baseline population. We received a total of 1623 responses, giving the response rate of $63.2 \%$. In the present analyses, we included all subjects who reported having current asthma in the 20-year follow-up ( $\mathrm{n}=164)$. The final study population consisted of 162 young adults aged 20-27, as two asthmatics did not answer the questions on exercise habits. The follow-up study protocol was approved by the Ethics Committee of the Oulu University Hospital.

\section{Definition of asthma and assessment of asthma control}

Asthma was defined based on questionnaire replies, applying pre-defined criteria that are shown in Figure 1. Current asthma was defined as "having ever doctor-diagnosed asthma" AND ["use of any asthma medication" OR "occurrence of asthma-related symptoms"] in the past 12 months. Asthma diagnosis was further checked in relation to the Finnish Social Insurance Institution's records on the reimbursement right for asthma medications [10].

The questionnaire asked about the cohort member's asthma symptoms, use of asthma medications, and exercising in the past 12 months. Asthma-related symptoms included wheezing, shortness of breath, cough, and phlegm production. Asthma control was evaluated by the occurrence of these symptoms in the past 12 months, and the asthma symptom score was calculated based on the frequencies of these symptoms. The frequency of symptoms was asked by the following questions: "How often during the past 12 months did you experience this symptom?" and the alternatives were: 1) “Almost daily", 2) “On 1-3 days per week”, 3) “On 1-3 days per month" and 4) "Less often than on 1 day per month". The alternatives were graded from 3 (corresponding to "Almost daily') to 0 points (corresponding to 'Less often than on 1 day per month'). The final asthma symptom score for each subject was calculated by combining the scores of all these four symptoms, giving a range for the asthma control of 0 to 12 .

\section{Assessment of regular exercise}

Assessment of regular exercise was based on information given in the self-administered questionnaire. The subjects were asked to report how many hours/week they usually exercised in 
the leisure time so that they became at least slightly breathless and sweaty. This question referred to exercising in the past 12 months. Subjects were then divided into four exercise quartiles according to the reported amount of weekly exercise. In the "No exercise" quartile the subjects reported exercising for 0 hours/week. The amounts of reported exercise in the other categories were: $>0$ $2.0 \mathrm{~h} /$ week for the "Low exercise" category, $>2.0$ - <5 h/week for the "Medium exercise" category, and $\geq 5.0 \mathrm{~h} /$ week for the "High exercise" category.

\section{Covariates}

Potential determinants of asthma control were considered as potential confounders and they were included as covariates in the model. These included gender, age, smoking, exposure to environmental tobacco smoke (ETS), and education. Body mass index (BMI) is also a potential determinant of asthma control, but it is influenced by regular exercise, i.e. it is in the causal pathway from exercise to asthma control, and therefore we did not include it as a confounder. Instead we conducted stratified analyses, where BMI was divided into low $(\leq 18)$, normal $(>18$ to 25 ), slightly overweight ( $>25$ to 30 ), and overweight $(>30)$ categories. Men and women were analyzed separately to evaluate potential differences between genders.

\section{Statistical methods}

We estimated the relation between regular exercise and asthma control, while adjusting for potential confounding. Further, we estimated the adjusted risk ratio for the occurrence of weekly asthmarelated symptoms according to the amount of exercising.

On the basis of our preliminary analyses, asthma control was on average worst in the "Low exercise" category rather than in the "No exercise" category, and the "No exercise" category was very small. Therefore, we used the "Low exercise" category as the reference category throughout the analyses.

We compared the mean of asthma symptom score and the risk of weekly asthma-related symptoms among these quartiles of regular exercising. We also assessed the effect of quantitative regular exercise (in $\mathrm{h} /$ week) on the asthma symptom score.

In the crude analyses, we compared the mean asthma symptom score between the quartiles of the amount of exercising. We estimated the adjusted mean score differences between the exercise and reference categories applying Poisson regression models using identity link function. For the relation between regular exercise and asthma symptom score, we also fitted a parametric 
quantitative variable of regular exercise (i.e. h/week). We estimated the adjusted risk ratios (RRs) of asthma-related symptoms contrasting each exercise category to the reference category applying Poisson regression with a logarithmic link function. These analyses were carried out using the GENMOD-procedure in the SAS software (SAS 9.3, SAS Institute, North Carolina).

\section{Results}

\section{Characteristics of the study population}

A total of 164 of the 1623 study subjects had current asthma, i.e. $9.4 \%$ of the baseline study population. Altogether 162 subjects of these $(98.8 \%$ ) were eligible to be used in our analyses (while 2 subjects with missing information on exercise habits were excluded). Table 1 presents characteristics of the study population according to the exercising quartiles. There were more women $(58.6 \%)$ than men $(41.4 \%)$ among asthmatics. Over one third (35.2\%) of the study subjects were current smokers, $8.6 \%$ were ex-smokers, while $56.2 \%$ were never smokers. $42.6 \%$ of all asthmatics were exposed to environmental tobacco smoke. Men reported the highest exercise amount more commonly than women. The amount of exercise reduced with active smoking and exposure to environmental tobacco smoke. Particularly in the overweight group, body mass index increased in the lower exercise quartiles. Subjects of the total study population exercised on average $3.88 \mathrm{~h} /$ week. The amount of mean weekly exercise was somewhat higher in men $(4.47 \mathrm{~h} /$ week $)$ compared to women $(3.46 \mathrm{~h} /$ week $)$.

Table 2 presents the prevalence of weekly asthma-related symptoms as well as the mean asthma symptom score according to the exercise quartiles. Asthma control was relatively good in the study population in general, when assessed based on the occurrence of the four main asthma-related symptoms. The prevalence of wheezing decreased from no to $\geq 5$ hours per week of regular exercise. For the other symptoms and the asthma symptom score, the relation between the prevalence of symptom and the amount of exercise was non-linear: the prevalences and the mean score decreased according to an increasing amount of weekly exercise from low to high exercise category, but the prevalence was also lower in the "No exercise" than "Low exercise" category.

\section{The relation between regular exercise and asthma symptom score}

Table 3 shows the relation between the amount of regular exercise and asthma symptom score. Regular exercise was fitted in Poisson regression analysis applying two different ways: as three indicator variables and as a continuous variable. There was a decrease in the mean asthma symptom 
score from the reference (i.e. "Low exercise") to the "High exercise" category. This observation changed only slightly when adjusting for confounding. In the final model, the asthma symptom score reduced statistically significantly by 0.09 points/1 hour of exercise per week (adjusted effect estimate: -0.09 , $95 \%$ CI: -0.17 to -0.00). Applying the "Low exercise" quartile as the reference category, "No exercise" reduced asthma symptom score by 0.59 points (-0.59; $95 \%$ CI: -2.28 to 1.09), "Medium exercise" by 0.66 points $(-0.66 ;-1.72$ to 0.39$)$, and "High exercise" by 1.13 (-1.13; -2.22 to -0.03 , i.e. statically significant), when adjusting for confounding. Among women, the asthma symptom score was statistically significantly greater in the "No exercise" quartile compared to the reference category.

Only 6 subjects of the study population were underweight. The effect of regular exercise on the asthma symptom score in this group was 0.77 (95\% CI: $-1.11-2.65$, i.e. statistically nonsignificant). Among normal weight subjects, the effect estimate of regular exercise on the symptom score was -0.35 (95 \% CI: $-0.95-0.23$ ), among the slightly overweight -0.81 (95\% CI: $-1.56--0.05$, i.e. statistically significant), and among the overweight -1.87 (95\% CI: $-2.61--1.12$, i.e. statistically significant). Thus, in addition to showing a decreasing trend of weekly asthmarelated symptoms with increasing exercise in general, such relations were statistically significant especially among the two overweight categories.

\section{The risk of individual asthma-related symptoms in relation to regular exercise}

The relation between regular exercising and the risk of individual asthma-related symptoms showed two different patterns: 1) The risk of wheezing decreased monotonously from no to high exercise category, and 2) The risk of cough, phlegm and shortness of breath was highest in the low exercise category and it decreased both in comparison to no and with increasing (high) amount of exercise.

Table 4 presents the RRs (risk ratios) of the asthma-related symptoms when contrasting to the "Low exercise" quartile of regular exercise, and per one hour per week of exercise. These results were not statistically significant. For wheezing, we used also "No exercise" as the reference category: in this model the risk of wheezing was significantly lower in the high exercise category compared to the reference category, with an adjusted RR of 0.29 (95\% CI: 0.10 to 0.91 ).

\section{Discussion}

\section{Main findings}

Our results of a population-based study from Espoo in Southern Finland showed that the occurrence 
of asthma-related symptoms was associated with the amount of weekly regular exercise reduces in young adults. If this association was considered causal, regular exercise should become an added important component of asthma self-management programs. The strongest association in the asthma symptom score was observed in relation to high-intensity exercise, showing a dose-dependent association between the amount of regular exercise and measures of asthma control. The association between regular exercise and asthma control was strongest among slightly overweight and overweight subjects.

\section{Validity of the results}

Our study population included young adults who had current asthma in the 20-year follow-up of this cohort study. The follow-up rate was $63.2 \%$, which we consider good when taking into account the age groups of this study population and the long follow-up period. The definition of asthma was first based on parent-reported and later on self-reported doctor-diagnosed asthma. Due to the national public health care system in Finland, people with symptoms of asthma have easy access to medical examination and diagnostic tests. The national reimbursement system for asthma medications provides an economic incentive for actually having potential asthma diagnosed by a physician $[9,11]$. These factors are likely to reduce any misclassification of asthma in our study population, at least among asthmatics with moderate to severe symptoms.

The determinant of interest was the duration of weekly exercise causing breathlessness and sweating. This was measured by information given in the self-administered questionnaire. According to our experience such an approach produces results that are most relevant as they are directly applicable to clinical practice. Although intensity of exercise is often measured by heart rate in laboratory conditions, in everyday practice most people pay attention to the duration of exercise and potential sweating as a consequence of exercising rather than measure their heart rate. Using duration as the measure of exercise increases the subject's ability to follow the recommendations given by the health care team.

We used the self-reported weekly frequency of asthma-related symptoms as the measure of asthma control. According to the American Thoracic Society/European Respiratory Society Guidelines [12] there is no gold standard for the definition of asthma, and therefore, there is neither gold standard for the assessment of asthma control. The occurrence of asthma-related symptoms represents a central component of the of asthma control [12]. The symptom occurrence is loosely related to the other three important components of asthma control, including airway obstruction, airway 
hyperresponsiveness, and airway inflammation. The lack of information on these other components as well as, for example, on the use of asthma medication is a relative limitation of the present study. According to the ATS/ERS Guidelines [12], asthma control should be evaluated by a combination of symptoms, as measured for example by the asthma symptom score, rather than by individual symptoms separately. Consistently with these guidelines, we observed the strongest positive effect of regular exercise on asthma control when applying the asthma symptom score rather than when applying individual asthma symptoms separately.

Any major selection bias is unlikely in the assessment of the relation between regular exercise and asthma control, as our study achieved a relatively high follow-up rate. Further, introduction of selection bias would require selection related to both occurrence of asthma symptoms and the amount of exercise. Information on exercise was self-reported and reporting could be related to the frequency of respiratory symptoms experienced. However, we found no studies suggesting that the occurrence of respiratory symptoms among asthmatics would influence reporting of the amount of exercise. A plausible scenario is that asthmatics with symptoms would overestimate the duration of exercise because of their disturbing symptoms. This would lead to underestimation of the beneficial effects of exercise on asthma control, i.e. in that case regular exercise would in reality have an even stronger beneficial effect on asthma control than estimated in our study.

We adjusted for several known or suggested determinants of asthma-related symptoms, i.e. asthma control, including gender, age, smoking, ETS exposure and education, as potential confounders by applying multivariate regression analyses. BMI was considered a potential effect modifier rather than a confounder, as explained in the Methods.

In the bivariate analyses, there was some indication that the relation between regular exercise and asthma control, especially the symptom score, is non-linear (see Table 2). The lowest asthma symptom score (i.e. the best asthma control) was observed in the "Low exercise" category ( $>0$ to 2 h per week) rather than in the "No exercise" category. The symptom score was lower with both increasing and decreasing amount of exercise. We elaborated further this possible non-linearity by using the "Low exercise" category rather than "No exercise" as the reference. We hypothesised that regular exercise improves asthma control, but the poorest asthma control could lead to complete or substantial avoidance of regular exercise. This would manifest as such non-linear relation. The finding of the higher asthma symptom score in the "no exercise group" compared to "low exercise group" is based on a rather small number of observations and could also be explained by chance. 
We collected information on regular exercise only in the 20-year follow-up survey and therefore, our findings are based on the cross-sectional analysis of data. Thus, our findings are consistent with the hypothesis that regular exercise improves asthma control, but we cannot establish a definite temporal relation between exercise and asthma control.

\section{Synthesis with previous knowledge}

Based on our systematic literature search, this is the first study that estimates the relation between the amount of regular exercise and asthma control among young adults. Our recently published systematic review and meta-analysis [6] showed that regular exercise improves physical fitness of adult asthmatics [6]. It has been suggested that regular exercise may have beneficial effects on the airway smooth muscle layer and on breathing pattern and that these effects could lead to reduced bronchial hyperresponsiveness [13]. In addition, better physical fitness may be associated with a higher threshold for experiencing breathlessness, and thus, a higher breathing reserve in daily activities of asthmatic subjects. A laboratory-based study of 68 asthmatics between 20 and 50 years of age [14] suggested that aerobic training leads to a significant decrease in airway inflammation, measured by sputum eosinophils and exhaled nitrogen oxide. The authors suggested that decreased inflammation of the airways may lead to increased resistance against infections, which would be beneficial for asthma control. A recent randomized trial of 58 clinically stable adult asthma patients reported that aerobic training improved (i.e. reduced) bronchial hyperresponsiveness and reduced asthma exacerbations [15].

In a previous longitudinal study, regular physical activity reduced the risk of asthma exacerbation among middle-aged women [16]. A Finnish population-based study initiated in the 1970s investigated 178 asthmatics older than 30 years and showed a significant positive association between the intensity of physical activity and spirometric lung function [17]. However, in intervention studies reviewed by Heikkinen et al. [6], evidence on potential effects of exercising on asthma control and/or quality of life was inconclusive, although some individual studies showed evidence of improving asthma control.

\section{Conclusions}

In conclusion, our findings are consistent with the hypothesis that regular exercising improves asthma control among young adults. Due to cross-sectional study design of this study, the temporality between exercise and asthma control cannot be definitely established, and therefore, 
these findings need strengthening by results from longitudinal studies, preferably from randomized controlled trials.

\section{Funding}

This study was supported by research grants by the Academy of Finland Grants No. 129419

(SALVE Research Program), No. 138691, and No. 266314, and by research grants from the Foundation of the Finnish Anti-Tuberculosis Association, the Research Foundation of the Pulmonary Diseases, Jalmari and Rauha Ahokas Foundation, Väinö and Laina Kivi Foundation, Ida Montin Foundation, the Oulu University Hospital, the Yrjö Jahnsson Foundation, and the University of Oulu. 


\section{References}

1. Gibson GJ, Loddenkemper R, Lundbäck B, Sibille Y. Respiratory health and disease in Europe: the new European Lung White Book. Eur Respir J 2013; 42: 559-563.

2. Peters SP, Ferguson G, Deniz Y, Reisner C. Uncontrolled asthma: A review of the prevalence, disease burden and options for treatment. Respir Med 2006; 100: 139-151.

3. Masoli M, Fabian D, Holt S, Beasley R. The global burden of asthma: executive summary of the GINA Dissemination Committee Report. Allergy 2005; 59: 469-478.

4. Goldney RD, Ruffin R, Fisher LJ, Wilson DH. Asthma symptoms associated with depression and lower quality of life: a population survey. Med J Aust 2003: 178; 437-441.

5. WHO. Global recommendations on physical activity for health. World Health Organization 2010. ISBN 9789241599979.

6. Heikkinen SAM, Quansah R, Jaakkola JJK, Jaakkola MS. Effects of regular exercise on adult asthma. Eur J Epidemiol 2012; 27: 394-407.

7. Ford ES, Health GW, Mannino DM, Redd SG. Leisure-time physical activity patterns among US adults with asthma. Chest 2003; 124: 432-437.

8. Oh EG, Kim SH, Park MS, Kim SK, Kim YS. Health behaviour and quality of life in Korean adults with respiratory disease: National Health Survey, 2005. Int J Tuberc Lung Dis 2009; 14: 772778.

9. Jaakkola JJ, Jaakkola N, Ruotsalainen R. Home dampness and molds as determinants of respiratory symptoms and asthma in pre-school children. J Expo Anal Environ Epidemiol 1993; 3 Suppl 1: 129-142.

10. Kansaneläkelaitos - The Social Insurance Institution of Finland. http://www.kela.fi/web/en. Date last updated: May 25 2016. Date last accessed: May 252016. 
11. Paaso EM, Jaakkola MS, Rantala AK, Hugg TT, Jaakkola JJ. Allergic diseases and asthma in the family predict the persistence and onset-age of asthma: a prospective cohort study. Respir Res 2014; 15: 152.

12. Reddel HK, Taylor R, Bateman ED, Boulet L-P, Boushey HA, Busse WW, Casale TB, Chanez P, Enright PL, Gibson PG, de Jongste JC, Kerstjens HAM, Lazarus SC, Levy ML, O'Byrne PM, Partridge MR, Pavord ID, Sears MR, Sterk PJ, Stoloff SW, Sullivan SD, Szefler SJ, Thomas MD, Wenzel SE. An Official American Thoracic Society/European Respiratory Society Statement: Asthma Control and Exacerbations. Am J Respir Crit Care Med 2009; 180: 59-99.

13. Lucas SR, Platts-Mills TAE. Physical activity and exercise in asthma: relevance to etiology and treatment. J Allergy Clin Immunol 2005; 115: 928-934

14. Mendes FA, Almeida FM, Cukier A, Steinmach R, Jacob-FilhoW, Martins MA, Carvalho CR. Effects of aerobic training on airway inflammation in asthmatic patients. Med Sci Sports Exerc 2011; 43: 197-203.

15. Del Giacco S, Garcia-Larsen V. Aerobic exercise training reduces bronchial hyperresponsiveness and serum pro-inflammatory cytokines in patients with asthma. Evid Based Med 2016; 21: 70.

16. Garcia-Aymerich J, Varraso R, Anto JM, Camargo CA. Prospective study of physical activity and risk of asthma exacerbations in older women. Am J Respir Crit Care Med 2009; 179: 999-1003.

17. Mälkiä E, Impivaara O. Intensity of physical activity and respiratory function in subjects with and without bronchial asthma. Scand J Med Sci Sports 1998; 8: 27-32. 


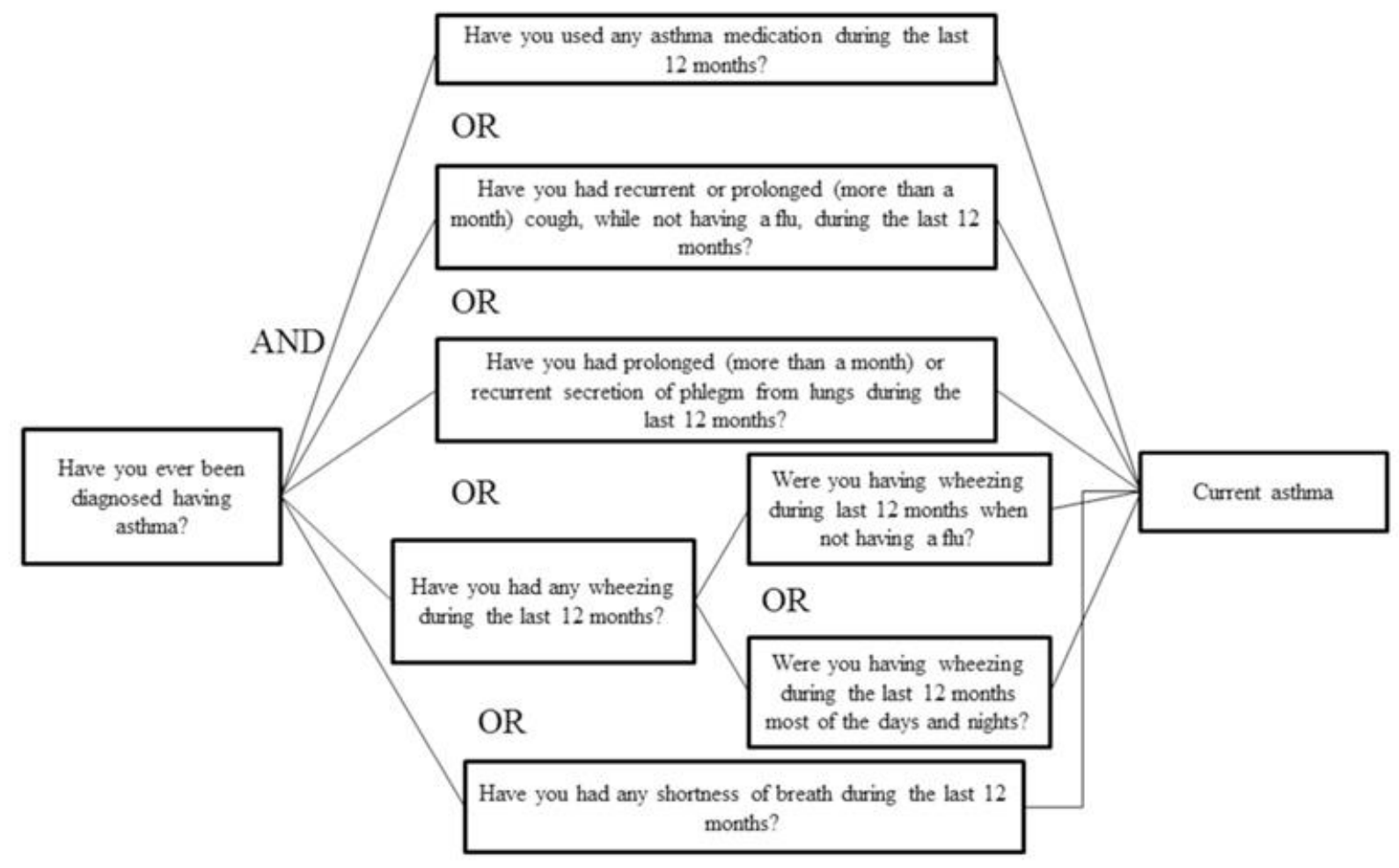

Figure 1

Figure 1. The questions defining current asthma. 
Table 1. Characteristics of the study population $(\mathrm{N}=164)$.

\begin{tabular}{|c|c|c|c|c|c|}
\hline \multirow[b]{2}{*}{ Characteristic } & \multicolumn{5}{|c|}{ Exercise (hours per week) } \\
\hline & $\begin{array}{l}\text { No } \\
(\mathbf{O} \text { h) }\end{array}$ & $\begin{array}{l}\text { Low } \\
(>0-2 \text { h })\end{array}$ & $\begin{array}{l}\text { Medium } \\
(>2<5 \mathrm{~h})\end{array}$ & $\begin{array}{l}\text { High } \\
(\geq \mathbf{5} \text { h })\end{array}$ & Total \\
\hline & $16(9.9 \%)$ & $53(32.7 \%)$ & $39(24.1 \%)$ & $54(33.3 \%)$ & $162 *$ \\
\hline Age mean, (range) & $22.9(20-26)$ & $23.2(20-26)$ & $22.8(20-26)$ & $22.8(20-26)$ & $22.9(20-26)$ \\
\hline Missing & \multicolumn{5}{|l|}{0} \\
\hline \multicolumn{6}{|l|}{ Gender } \\
\hline Men & $7(43.8 \%)$ & $20(37.7 \%)$ & $12(30.8 \%)$ & $28(51.9 \%)$ & $67(41.4 \%)$ \\
\hline Women & $9(56.3 \%)$ & $33(62.3 \%)$ & $27(69.2 \%)$ & $26(48.2 \%)$ & $95(58.6 \%)$ \\
\hline Missing & \multicolumn{5}{|l|}{0} \\
\hline \multicolumn{6}{|l|}{ Body mass index } \\
\hline$\leq 18$ & $1(6.3 \%)$ & $3(5.8 \%)$ & $1(2.7 \%)$ & $1(1.9 \%)$ & $6(3.8 \%)$ \\
\hline$>18 \leq 25$ & $7(43.8 \%)$ & $32(61.5 \%)$ & $27(73.0 \%)$ & $35(66.0 \%)$ & $\begin{array}{l}101(63.9 \\
\%)\end{array}$ \\
\hline$>25 \leq 30$ & $4(25.0 \%)$ & $12(23.1 \%)$ & $7(18.9 \%)$ & $15(28.3 \%)$ & $38(24.1 \%)$ \\
\hline$>30$ & $4(25.0 \%)$ & $5(9.6 \%)$ & $2(5.4 \%)$ & $2(3.8 \%)$ & $13(8.2 \%)$ \\
\hline Missing & \multicolumn{5}{|l|}{4} \\
\hline \multicolumn{6}{|l|}{ Education } \\
\hline $\begin{array}{l}\text { Comprehensive or } \\
\text { upper secondary }\end{array}$ & $6(37.5 \%)$ & $25(47.2 \%)$ & $19(48.7 \%)$ & $30(57.7 \%)$ & $80(50.0 \%)$ \\
\hline Vocational school & $7(43.8 \%)$ & $17(32.1 \%)$ & $6(15.4 \%)$ & $11(21.2 \%)$ & $41(25.6 \%)$ \\
\hline Academic degree & $3(18.8 \%)$ & $11(20.8 \%)$ & $14(35.9 \%)$ & $11(21.2 \%)$ & $39(24.4 \%)$ \\
\hline Missing & \multicolumn{5}{|l|}{2} \\
\hline \multicolumn{6}{|l|}{ Smoking } \\
\hline Never smoker & $8(50.0 \%)$ & $26(49.1 \%)$ & $18(46.2 \%)$ & $39(72.2 \%)$ & $91(56.2 \%)$ \\
\hline Ex-smoker & $0(0.0 \%)$ & $5(9.4 \%)$ & $5(12.8 \%)$ & $4(7.4 \%)$ & $14(8.6 \%)$ \\
\hline Current smoker & $8(50.0 \%)$ & $22(41.5 \%)$ & $16(41.0 \%)$ & $11(20.4 \%)$ & $57(35.2 \%)$ \\
\hline Missing & \multicolumn{5}{|l|}{0} \\
\hline \multicolumn{6}{|c|}{ Second hand smoking } \\
\hline Yes & $10(62.5 \%)$ & $27(50.1 \%)$ & $18(46.2 \%)$ & $14(25.9 \%)$ & $69(42.6 \%)$ \\
\hline No & $6(38.0 \%)$ & $26(49.1 \%)$ & $21(53.9 \%)$ & $40(74.1 \%)$ & $93(57.4 \%)$ \\
\hline Missing & \multicolumn{5}{|c|}{0} \\
\hline
\end{tabular}

*Information on exercise missing for 2 subjects 
Table 2. The occurrence of weekly asthma-related symptoms and asthma symptoms score according to the amount of exercise (in h/week).

\begin{tabular}{|c|c|c|c|c|c|}
\hline \multirow[b]{2}{*}{ Symptom } & \multicolumn{4}{|c|}{ Exercise (in hours per week) } & \multirow[t]{2}{*}{ Total } \\
\hline & $\begin{array}{l}\text { No } \\
(\mathbf{0} \text { h) }\end{array}$ & $\begin{array}{l}\text { Low } \\
(>0 \text { - } 2 \text { h })\end{array}$ & $\begin{array}{l}\text { Medium } \\
(>2-<5 \mathrm{~h})\end{array}$ & $\begin{array}{l}\text { High } \\
(\geq \mathbf{5} \text { h })\end{array}$ & \\
\hline Wheezing & $5(31.3 \%)$ & $7(13.2 \%)$ & $4(10.3 \%)$ & $4(7.4 \%)$ & $20(12.3 \%)$ \\
\hline $\begin{array}{l}\text { Shortness of } \\
\text { breath }\end{array}$ & $2(12.5 \%)$ & $9(17.0 \%)$ & $3(7.7 \%)$ & $3(5.8 \%)$ & $17(10.6 \%)$ \\
\hline Cough & $3(18.8 \%)$ & $10(19.2 \%)$ & $4(10.3 \%)$ & $6(11.1 \%)$ & $23(14.3 \%)$ \\
\hline Phlegm & $3(18.8 \%)$ & $13(24.5 \%)$ & $10(25.6 \%)$ & $8(14.8 \%)$ & $34(20.1 \%)$ \\
\hline $\begin{array}{l}\text { Asthma } \\
\text { symptom score } \\
\text { Mean (95\% CI) }\end{array}$ & $4.13(3.13-5.12)$ & $4.33(3.78-4.90)$ & $3.67(3.07-4.27)$ & $2.85(2.40-3.30)$ & $3.66(3.23-4.10)$ \\
\hline
\end{tabular}

Table 3. The effect of regular exercise on the asthma symptom score used to assess asthma control.

\begin{tabular}{|c|c|c|c|c|c|}
\hline & $\begin{array}{l}\text { No } \\
(\mathbf{0} \text { h) }\end{array}$ & $\begin{array}{l}\text { Reference* }^{*} \\
(>0-2 \text { h })\end{array}$ & $\begin{array}{l}\text { Medium } \\
(>2-<5 \mathrm{~h})\end{array}$ & $\begin{array}{l}\text { High } \\
(\geq 5 \mathrm{~h})\end{array}$ & Per hour** \\
\hline Total (n) & 16 & 53 & 39 & 54 & \\
\hline Crude & $\begin{array}{l}-0.21 \\
(-2.05-1.62)\end{array}$ & 4.34 & $\begin{array}{l}-0.67 \\
(-1.76-0.41)\end{array}$ & $\begin{array}{l}-1.49 \\
(-2.51--0.46)\end{array}$ & $\begin{array}{l}-0.13 \\
(-0.20--0.07)\end{array}$ \\
\hline Adjusted & $\begin{array}{l}-0.59 \\
(-2.28-1.09)\end{array}$ & 3.92 & $\begin{array}{l}-0.66 \\
(-1.72-0.39)\end{array}$ & $\begin{array}{l}-1.13 \\
(-2.22--0.03)\end{array}$ & $\begin{array}{l}-0.09 \\
(-0.17--0.00)\end{array}$ \\
\hline \multicolumn{6}{|l|}{ Men } \\
\hline Crude & $\begin{array}{l}0.92 \\
(-2.20-4.06)\end{array}$ & 4.50 & $\begin{array}{l}-1.33 \\
(-2.96-0.29)\end{array}$ & $\begin{array}{l}-1.79 \\
(-3.22--0.35)\end{array}$ & $\begin{array}{l}-0.13 \\
(-0.22--0.05)\end{array}$ \\
\hline Adjusted & $\begin{array}{l}0.44 \\
(-2.23-3.12)\end{array}$ & 3.82 & $\begin{array}{l}-1.37 \\
(-2.81-0.07)\end{array}$ & $\begin{array}{l}-1.30 \\
(-2.66-0.07)\end{array}$ & $\begin{array}{l}-0.10 \\
(-0.22-0.01)\end{array}$ \\
\hline \multicolumn{6}{|l|}{ Women } \\
\hline Crude & $\begin{array}{l}-1.13 \\
(-3.05-0.79)\end{array}$ & 4.24 & $\begin{array}{l}-0.35 \\
(-1.76-1.05)\end{array}$ & $\begin{array}{l}-1.24 \\
(-2.69-0.21)\end{array}$ & $\begin{array}{l}-0.12 \\
(-0.25-0.01)\end{array}$ \\
\hline Adjusted & $\begin{array}{l}-1.58 \\
(-3.10--0.06)\end{array}$ & 4.11 & $\begin{array}{l}-0.24 \\
(-1.59-1.12)\end{array}$ & $\begin{array}{l}-1.03 \\
(-2.33-0.27)\end{array}$ & $\begin{array}{l}-0.07 \\
(-0.17-0.03)\end{array}$ \\
\hline
\end{tabular}

Results are shown as Beta $(95 \% \mathrm{CI})$, low exercise group as the reference category.

Adjusting for: gender, age, smoking, environmental tobacco smoke exposure, and education.

*Represents the intercept in the regression model, **Excluding subjects in the no category 
Table 4. The effect of regular exercise on weekly symptom occurrence.

\begin{tabular}{|c|c|c|c|c|c|c|c|c|c|}
\hline \multirow{2}{*}{$\begin{array}{l}\text { Exercise } \\
\text { (h per } \\
\text { week) } \\
\text { Symptom }\end{array}$} & \multicolumn{2}{|l|}{$\begin{array}{l}\text { No } \\
(\mathbf{0} \text { h) }\end{array}$} & \multirow[t]{2}{*}{$\begin{array}{l}\text { Reference } \\
(>0-2 \text { h })\end{array}$} & \multicolumn{2}{|l|}{$\begin{array}{l}\text { Medium } \\
(>2-<5 \mathrm{~h})\end{array}$} & \multicolumn{2}{|l|}{$\begin{array}{l}\text { High } \\
(\geq 5 \mathrm{~h})\end{array}$} & \multicolumn{2}{|l|}{ Per hour* } \\
\hline & $\begin{array}{l}\text { Crude } \\
\text { RR } \\
(95 \% \mathrm{CI})\end{array}$ & $\begin{array}{l}\text { Adjusted } \\
\text { RR } \\
(95 \% \mathrm{CI})\end{array}$ & & $\begin{array}{l}\text { Crude } \\
\text { RR } \\
(95 \% \mathrm{CI})\end{array}$ & $\begin{array}{l}\text { Adjusted } \\
\text { RR } \\
(95 \% \mathrm{CI})\end{array}$ & $\begin{array}{l}\text { Crude } \\
\text { RR } \\
(95 \% \mathrm{CI})\end{array}$ & $\begin{array}{l}\text { Adjusted } \\
\text { RR } \\
(95 \% \mathrm{CI})\end{array}$ & $\begin{array}{l}\text { Crude } \\
\text { RR } \\
(95 \% \mathrm{CI})\end{array}$ & $\begin{array}{l}\text { Adjusted } \\
\text { RR } \\
(95 \% \mathrm{CI})\end{array}$ \\
\hline Wheezing & $\begin{array}{l}2.37 \\
(0.87-6.44)\end{array}$ & $\begin{array}{l}2.44 \\
(0.98-6.07)\end{array}$ & 1.00 & $\begin{array}{l}0.78 \\
(0.24-2.47)\end{array}$ & $\begin{array}{l}0.78 \\
(0.23-2.65)\end{array}$ & $\begin{array}{l}0.56 \\
(0.17-1.80)\end{array}$ & $\begin{array}{l}0.73 \\
(0.19-2.75)\end{array}$ & $\begin{array}{l}0.90 \\
(0.78-1.04)\end{array}$ & $\begin{array}{l}0.94 \\
(0.81-1.10)\end{array}$ \\
\hline Cough & $\begin{array}{l}0.98 \\
(0.31-3.12)\end{array}$ & $\begin{array}{l}0.90 \\
(0.29-2.81)\end{array}$ & 1.00 & $\begin{array}{l}0.53 \\
(0.18-1.57)\end{array}$ & $\begin{array}{l}0.57 \\
(0.20-1.60)\end{array}$ & $\begin{array}{l}0.58 \\
(0.23-1.48)\end{array}$ & $\begin{array}{l}0.84 \\
(0.30-2.34)\end{array}$ & $\begin{array}{l}0.93 \\
(0.81-1.06)\end{array}$ & $\begin{array}{l}0.96 \\
(0.85-1.09)\end{array}$ \\
\hline $\begin{array}{l}\text { Shortness } \\
\text { of breath }\end{array}$ & $\begin{array}{l}0.73 \\
(1.18-3.07)\end{array}$ & $\begin{array}{l}0.78 \\
(0.23-2.69)\end{array}$ & 1.00 & $\begin{array}{l}0.45 \\
(0.13-1.56)\end{array}$ & $\begin{array}{l}0.46 \\
(0.13-1.65)\end{array}$ & $\begin{array}{l}0.34 \\
(0.10-1.19)\end{array}$ & $\begin{array}{l}0.41 \\
(0.11-1.52)\end{array}$ & $\begin{array}{l}0.82 \\
(0.67-1.01)\end{array}$ & $\begin{array}{l}0.85 \\
(0.68-1.06)\end{array}$ \\
\hline Phlegm & $\begin{array}{l}0.76 \\
(0.24-2.35)\end{array}$ & $\begin{array}{l}0.70 \\
(0.22-2.11)\end{array}$ & 1.00 & $\begin{array}{l}1.04 \\
(0.51-2.13)\end{array}$ & $\begin{array}{l}1.15 \\
(0.55-2.44)\end{array}$ & $\begin{array}{l}0.60 \\
(0.27-1.34)\end{array}$ & $\begin{array}{l}0.85 \\
(0.37-1.97)\end{array}$ & $\begin{array}{l}0.91 \\
(0.82-1.01)\end{array}$ & $\begin{array}{l}0.95 \\
(0.86-1.04)\end{array}$ \\
\hline
\end{tabular}

$\mathbf{R R}=$ risk ratio, $\mathrm{CI}$ = confidence interval; adjusting for: gender, age, smoking, environmental tobacco smoke exposure, and education

*Excluding subjects in the no category 